\title{
The cardiac implications of breast reconstruction using the internal mammary artery as the recipient vessel
}

\author{
Amanda J Fortin MD MSc FRCSC, H Brian Evans MD FRCSC, Michael WA Chu MD FRCSC
}

AJ Fortin, HB Evans, MWA Chu. The cardiac implications of breast reconstruction using the internal mammary artery as the recipient vessel. Can J Plast Surg 2012;20(1):e16-e18.

BACKGROUND: Microsurgical breast reconstruction is a popular choice in breast reconstruction. Recipient vessel use for these autologous tissue reconstructions has shifted from the thoracodorsal to the internal mammary vessels. Coronary artery bypass (CAB) surgery remains the optimal revascularization strategy in patients with significant, diffuse coronary artery disease. The conduits of choice for coronary revascularization are the internal mammary arteries (IMA) because of their superior long-term graft patency rate and improved patient survival.

OBJECTIVE: To review the cardiac risk factors in the breast reconstruction population, and to report the incidence of postoperative cardiac events at the London Health Sciences Centre, London, Ontario. The authors present the index cases illustrating cardiac complications following the use of internal mammary vessels.

METHOD: A retrospective, single-centre, cumulative audit of breast reconstruction practice from 2005 to 2009 was conducted. A total of 81 patients undergoing autologous breast reconstruction were reviewed. Two women were noted to have experienced postoperative myocardial infarction requiring intervention. Both were noted to have triple-vessel disease, an indication for CAB; however, during the breast reconstruction, their IMAs had been utilized. As a result, both women subsequently underwent triple-vesssel percutaneous intervention, with one woman later requiring $\mathrm{CAB}$ without IMA because of recurrent ischemia.

CONCLUSION: While there is limited overlap with the breast reconstruction and cardiac disease population, there can be significant cardiac health implications in the postoperative status (both short and long term) of women undergoing autologous breast reconstruction using the IMAs as recipient vessels.

Key Words: Breast reconstruction; Coronary artery bypass; Internal mammary artery; Internal thoracic artery; Microsurgery

$\mathrm{T}$ he number of women undergoing reconstruction following breast cancer treatment and prophylactic mastectomies has been increasing steadily. These women are generally young and active, and have a good life expectancy; however, as this population ages, the incidence of concomitant ischemic heart disease increases. Currently, the internal mammary arteries (IMAs) are used almost exclusively for autologous free flap breast reconstruction $(1,2)$. No study has examined the possible impact of IMA use in breast reconstruction on coronary revascularization and potential lifetime morbidity.

Heart disease is the leading cause of death in American women. One in 10 women, 45 to 64 years of age, has some form of heart disease, and this increases to one in four women older than 65 years of age (3). Coronary artery bypass surgery can improve anginal symptoms and, unlike percutaneous coronary intervention, will improve life expectancy in patients with coronary artery disease when the IMAs are used for revascularization $(4,5)$. Evidence regarding the superior patency of IMA grafts over any other conduit or intracoronary revascularization mechanism is clear (6-8). Selection of the IMA for free flap breast reconstruction may provide a better cosmetic result;

\section{Les répercussions cardiaques de la reconstruction mammaire lorsque l'artère mammaire interne sert de vaisseau receveur}

HISTORIQUE : La reconstruction mammaire microchirurgicale est un choix populaire. Le recours à des vaisseaux receveurs dans le cadre de ces reconstructions par tissus autologues est passé des vaisseaux thoracodorsaux aux vaisseaux mammaires internes. Le pontage aortocoronarien (PAC) demeure la stratégie de revascularisation optimale chez les patients ayant une coronaropathie diffuse. Les artères mammaires internes (AMI) représentent des conduits de choix pour la revascularisation coronarienne en raison du taux de perméabilité supérieur de la greffe à long terme et du meilleur taux de survie des patients.

OBJECTIF : Analyser les facteurs de risque cardiaque des personnes subissant une reconstruction mammaire et signaler l'incidence d'événements cardiaques postopératoires survenus au London Health Sciences Centre de London, en Ontario. Les auteurs présentent les cas de référence démontrant des complications cardiaques après l'utilisation des vaisseaux mammaires internes.

MÉTHODOLOGIE : Les chercheurs ont procédé à une vérification cumulative monocentriquerétrospective des pratiques de reconstruction mammaire entre 2005 et 2009. Au total, ils ont analysé 81 patients ayant subi une reconstruction mammaire par tissus autologues. Ils ont constaté que deux femmes avaient subi un infarctus du myocarde après l'opération, lequel avait nécessité une intervention. Toutes deux avaient unetriple vasculopathie, ce qui constitue une indication de PAC, mais pendant la reconstruction mammaire, on avait utilisé leurs AMI. Par conséquent, les deux femmes ont ensuite subi une triple intervention percutanée, et l'une d'elles a ensuite dû subir un PAC sans AMI en raison d'une ischémie récurrente.

CONCLUSION : Le chevauchement entre la population de personnes qui subissent une reconstruction mammaire et celle qui est atteinte d'une maladie cardiaque est limité. Toutefois, les femmes qui subissent une reconstruction mammaire par tissus autologues chez qui les AMI servent de vaisseaux receveurs peuvent voir leur état postopératoire (à court et à long terme) entaché par d'importants effets cardiaques.

however, this could potentially be at the cost of a shorter life expectancy and poorer quality of life, if ischemic heart disease is concomitantly present or becomes a health issue later in life.

The use of the IMA for breast reconstruction should be studied from a cardiac health standpoint for multiple reasons: the first being the ability to give patients informed consent before proceeding with breast reconstruction. The second is to potentially alter the methods by which autologous breast reconstruction is performed, or at least contemplate alternative techniques that may preserve the internal mammary (IM) vessels.

\section{METHODS}

A retrospective, cumulative audit of the London Health Sciences Centre (London, Ontario) breast reconstruction practice from 2005 to 2009 was conducted using billing records. All patients undergoing microsurgical breast reconstruction were included. Surgery was performed by two staff plastic surgeons at University Hospital, London Health Sciences Centre. Patient demographics, cardiac risk factors (smoking, obesity, diabetes, hypertension, previous cardiac events and 
TABLE 1

\section{Summary of postoperative complications}

\begin{tabular}{lc}
\hline Complication & $\mathbf{n ~ ( \% )}$ \\
\hline Flap loss & $2(1.7)$ \\
Mastectomy flap necrosis & $4(11.7)$ \\
Fat necrosis in flap & $17(14.8)$ \\
Breast hematoma & $9(7.8)$ \\
Transfusion & $7(8.6)$ \\
Hernia & $1(0.8)$ \\
Myocardial infarction & $2(2.4)$ \\
\hline
\end{tabular}

family history) and reconstructive details were collected from the charts. The incidence of cardiac events following reconstruction and other postoperative complications were reviewed.

\section{RESULTS}

A total of 81 patients were identified between 2005 and 2009. Given the incidence of 34 bilateral breast reconstructions, a total of 115 flaps were reviewed. Sixty-six of 115 reconstructions were performed by the senior surgeon (HBE). Forty-seven cases were performed as delayed breast reconstructions, while 34 were immediate reconstructions. The mean patient age was 49 years (range 24 to 74 years). Of the pathological diagnoses $(n=81)$, tumour characteristics included 60 patients with invasive ductal carcinoma and 13 patients with ductal carcinoma in situ; five patients underwent prophylactic mastectomies. Seventeen patients underwent previous radiation, while 55 patients underwent chemotherapy.

From a cardiac risk factor assessment, 14 patients were current smokers, 14 were exsmokers (longer than three months) and 53 were nonsmokers. Seventeen patients had a history of hypertension, six had high cholesterol and one had a history of ischemic heart disease. Five patients had disclosed a family history of heart disease; however, the screening process for heart disease was not consistent. Only one patient had a history of diabetes. The average body mass index (BMI) was $27 \mathrm{~kg} / \mathrm{m}^{2}$ (range $19 \mathrm{~kg} / \mathrm{m}^{2}$ to $40 \mathrm{~kg} / \mathrm{m}^{2}$ ), with only six patients having a BMI of $30 \mathrm{~kg} / \mathrm{m}^{2}$ or greater.

An analysis of microsurgical methods revealed that the vast majority of flaps were anastomosed to the IM vessels (111 of 115). Four flaps were joined to the thoracodorsal vessels. When the IM vessels were prepared, the majority were exposed through removal of the third costal cartilage (73 vessels); in four instances, the second costal cartilage and, in eight cases, the fourth costal cartilage was removed. Of note, two instances had flaps anastomosed to the IMA in a retrograde fashion because of anastomotic issues. Similarly, three IM veins were used in a retrograde fashion. Only eight cases required the use of two veins per flap. The type of flaps harvested for breast reconstruction included the muscle-sparing transverse rectus abdominus musculocutaneous flap $(n=18)$, the deep inferior epigastric perforator flap $(n=89)$ and the superficial inferior epigastric artery flap $(n=8)$. Of these flaps, only six required mesh for repair of the rectus fascial defect.

The postoperative complications are summarized in Table 1 . There were two flap losses, 17 documented cases of fat necrosis, nine hematomas and 14 instances of delayed healing. Two women experienced postoperative myocardial infarctions requiring urgent cardiac catheterization and subsequent multivessel percutaneous coronary intervention with coronary stent implantation. One of the women subsequently underwent coronary artery bypass surgery. The average stay in hospital was six days, (range three to 16 days). The two patients who experienced postoperative cardiac events were smokers.

\section{Postoperative cardiac events}

Case 1: The first patient was a 59-year-old woman with a 20 pack-year history of smoking. Her BMI was $27 \mathrm{~kg} / \mathrm{m}^{2}$, but she was otherwise healthy. She underwent a delayed unilateral breast reconstruction with a myocardial infarction occurring on postoperative day 3 . Her

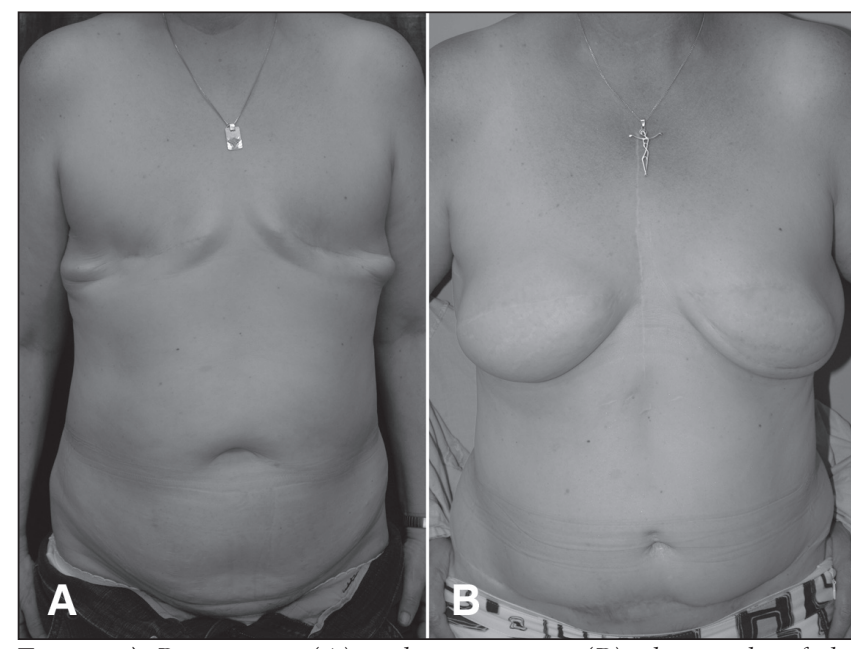

Figure 1) Preoperative (A) and postoperative (B) photographs of the patient described in case 2. Note the sternotomy scar

treatment included percutaneous stenting of triple vessel disease as a result of her most recent surgery using the IM vessels. Her recovery was uneventful.

Case 2: The second patient was a 56-year-old woman. She was a recent exsmoker (40 pack-year history), with a medical history of hypertension and diabetes. She had undergone bilateral delayed breast reconstruction; however, her course was complicated by postoperative anemia requiring a blood transfusion. She experienced a myocardial infarction on postoperative day 4. She also underwent percutaneous stenting of triple vessel disease. Other complications in this case included fat necrosis in the flap as well as dehiscence of her abdominal wound. Furthermore, as a result of recurrent myocardial ischemia, this woman required coronary artery bypass surgery within one year (Figure 1). Her saphenous vein and radial arteries were used as conduits as a result of both IMAs being harvested for breast reconstruction.

\section{DISCUSSION}

Options for breast reconstruction have changed significantly over the past few decades, with an increase in free flap autologous reconstructions. The IM vessels are known to have significant advantages over those of the thoracodorsal vessels and are used almost exclusively (2). It is often mentioned in speculation that the use of the IM vessels may be deleterious to patients who develop cardiac disease in that the preferred conduit choice for coronary bypass surgery (the IMA) has been sacrificed in the breast reconstruction. However, there has been minimal patient-physician interaction, or academic research, to consider whether microsurgical reconstruction using the IMA is sacrificing a major conduit for cardiac salvage, ultimately having an impact on patient morbidity and survival.

The present retrospective chart review of all microsurgical breast reconstructions performed at our institution from 2005 to 2009 shows that two of 81 patients identified experienced postoperative myocardial infarctions. Flap loss and other complication statistics were comparable with previously published figures. In the two patients who experienced cardiac complications, additional investigations revealed significant triple vessel coronary artery disease, normally mandating multivessel coronary artery bypass surgery using the IM vessels for the optimal long-term relief from angina and, thus, conferring superior survival benefits. Because the IM vessels had been used for breast reconstruction, these patients underwent angioplasty and stenting instead. Angioplasty does not offer the same survival and anginal-free state as multivessel coronary artery bypass. In fact, percutaneous coronary intervention has never been proven to have any life-prolonging benefits (8). Their treatment course may have ultimately been different had they not undergone breast reconstruction using IM vessels. 
While the small sample size of the breast reconstruction population in the present study may over- or underestimate the true risk or incidence, it certainly raises the concern that the issue of use of the IMA in breast reconstruction warrants more attention.

With regard to choice of recipient vessels in free flap breast reconstruction, the main decision is between the use of thoracodorsal and IM vessels. The IMA originates from the subclavian artery, runs ventral to the parietal pleura and transversus thoracis, and dorsal to the costal cartilage. The IMA divides into the superior epigastric artery and musculophrenic artery at the sixth intercostal space (9). The main benefits of using the IM vessels include medial flap positioning and avoidance of lateral fullness; the ability to use a flap with a shorter pedicle; consistent location of large-calibre vessels; and lack of a scarred bed with potentially unreliable recipient vessel flow, which can occur in delayed reconstruction following axillary dissection $(2,10)$. Drawbacks of the IM site include its unpredictable venous anatomy, the fragility of the IM veins and the risk of pneumothorax $(11,12)$. Movement during respiration can complicate microsurgical anastomosis, but may improve venous outflow via the negative pressure during inspiration (2).

The diameter of the IMA at the level of the fourth rib is often $2 \mathrm{~mm}$, and maintains a reasonable diameter throughout its length ( $1 \mathrm{~mm}$ to $2.5 \mathrm{~mm}$ ) (9). In contrast to the IMA, the venous anatomy is more variable. Commonly described preparation of the IM vessels for microvascular anastomosis includes removal of the medial portion of the third costal cartilage (13). The third rib is often chosen primarily for venous diameter; however, anastamosis has been described anywhere from the second to the fifth intercostal space (14). Most often (94\%) there is a single, medially positioned, comitant vein (9). Hefel et al (9) reported that the IMA and IM vein are suitable for microsurgery at the level of the fourth rib, which certainly, was supported by several cases in this series. It is not currently known whether the use of the IMA at any level for breast reconstruction is compatible with future use in coronary artery bypass surgery; however, intuitively, one would expect that the longer the length of virgin vessel, the more likely the possibility of future use for coronary bypass.

Ischemic heart disease remains the most common cause of death for women in developed countries. Despite current trends in

\section{REFERENCES}

1. Barnsley GP, Sigurdson L, Kirkland S. Barriers to breast reconstruction after mastectomy in Nova Scotia. Can J Surg 2008;51:447-52.

2. Nincovic M, Anderl J, Hefel L, Schwabegger A, Wechselberger G. Internal mammary vessels: A reliable recipient system for free flaps in breast reconstruction. Br J Plastic Surgery 1995;48:533-9.

3. Rosamond W, Flegal K, Furie K, et al. AHA statistical update. Heart disease and stroke statistics - 2008 update. A Report From the American Heart Association Statistics Committee and Stroke Statistics Subcommittee. Circulation 2008:117:e50-60.

4. Loop FD, Lytle BW, Cosgrove DM, et al. Influence of the internal-mammary-artery graft on 10-year survival and other cardiac events. N Engl J Med 1986;314:1-6.

5. Fitzgibbon GM, Kafka HP, Leach AJ, Keon WJ, Hooper GD, Burton JR. Coronary bypass graft fate and patient outcome: Angiographic follow-up of 5,065 grafts related to survival and reoperation in 1,388 patients during 25 years. J Am Coll Cardiol 1996;28:616-26.

6. Goldman S, Zadina K, Moritz T, et al. Long-term patency of saphenous vein and left internal mammary artery grafts after coronary artery bypass surgery: Results from a Department of Veterans Affairs Cooperative Study. J Am Coll Cardiol 2004;44:2149-56.

7. Tatoulis J, Buxton BF, Fuller JA. Patencies of 2127 arterial to coronary conduits over 15 years. Ann Thorac Surg 2004;77:93-101. percutaneous coronary intervention and the recent popularity of drugeluting stents, the strongest, most robust evidence with the longest follow-up still fervently supports coronary artery bypass surgery as the gold standard therapy for left main coronary artery disease, triple vessel disease and two vessel disease with proximal left anterior descending artery involvement (5). Evidence regarding the superior patency of IMA grafts over any other conduit or intracoronary revascularization mechanism is clear. Recent studies have suggested patency rates of between $95 \%$ and $99 \%$ at 10 years (6-8), and $88 \%$ patency at 15 years (8). Alternatively, saphenous vein grafts have an expected patency rate of approximately $50 \%$ to $60 \%$ at 10 years. The most persuasive information about the left IMA graft is that, unlike saphenous vein grafts or coronary stents, the left IMA-left anterior descending bypass is the only form of coronary revascularization that has been associated with improved early and late patient survival $(4,15)$. In general, most cardiac surgeons reserve bilateral IMA grafting for young, nondiabetic patients with an appropriate body habitus.

\section{CONCLUSION}

The finding of a low but significant incidence of postoperative cardiac ischemic events following breast reconstruction is concerning. There is a paucity of information on how significant the use of the IMA in breast reconstruction patients will be as a determinant of successful cardiac rehabilitation in the patient's future. More research needs to be performed to further quantify the true impact of using the IMA for breast reconstruction and the implications of excluding it as a future option for coronary revascularization. Limitations to the present study include the small sample size and the short length of follow-up. Both larger sample sizes and longer-term follow-up periods are necessary to provide adequate statistical power to our findings. Indeed, the impact on cardiac health may not become evident in the young breast reconstruction patients until they reach the age of increased cardiac risk.

DISCLOSURES: The authors have no financial disclosures or conflicts of interest to declare.

8. Cameron A, Davis KB, Green G, Schaff HV. Coronary bypass surgery with internal-thoracic-artery grafts - effects on survival over a 15-year period. N Engl J Med 1996;334:216-9.

9. Hefel L, Schwabegger A, Ninkovic M, et al. Internal mammary vessels: Anatomical and clinical considerations. Br J Plast Surg 1995;48:527-32.

10. Moran SL, Nava G, Benham AH Serletti JM. An outcome analysis comparing the thoracodorsal and internal mammary vessels as recipient sites for microvascular breast reconstruction: A prospective study of 100 patients. Plast Reconstr Surg 2003;111:1876-82.

11. Kavouni A, Shibu M. Problems associated with the use of the internal mammary vessels as recipients for free flap breast reconstruction. Br J Plast Surg 1999;52:597.

12. Shaw WW. Breast reconstruction by superior gluteal microvascular free flaps without silicone implant. Plast Reconstr Surg 1983;72:490.

13. Feng LJ. Recipient vessels in free-flap breast reconstruction: A study of the internal mammary and thoracodorsal vessels. Plast Reconstr Surg 1997;99:405-16.

14. Clark CP, Rohrich RJ, Copit S, et al. An anatomic study of the internal mammary veins: Clinical implications for free-tissue transfer breast reconstruction. Plast Reconstr Surg 1997;99:400-4.

15. Dabal RJ, Goss JR, Maynard C, Aldea GS. The effect of left internal mammary artery utilization on short-term outcomes after coronary revascularization. Ann Thorac Surg 2003;76:464-70. 